\title{
Can ambulatory biofeedback help a transgender woman speak at a higher pitch?
}

Dominique Morsomme, SLT, PhD ${ }^{\mathrm{a}}$; Angélique Remacle, SLT, $\mathrm{PhD}^{\mathrm{a}, \mathrm{b}}$

${ }^{a}$ Department of Speech and Language Therapy, Voice Unit, University of Liège, Belgium

${ }^{b}$ Fund for Scientific Research FNRS, Brussels, Belgium

Paper accepted for publication in Logopedics Phoniatrics Vocology

Correspondence concerning this article should be addressed to Dominique Morsomme, Logopédie de la voix, Département de Logopédie, Université de Liège, B-38, Rue de l'Aunaie, 30, 4000 Liège, Belgium.

Email may be sent to Dominique.Morsomme@uliege.be 


\section{Abstract}

Voice feminization for transgender women remains a challenge. The fundamental frequency of the voice $\left(f_{0}\right)$ is one of the main parameters contributing to the perception of gender. One of the aims of voice therapy is to help transgender women acquire a new vocal motor behavior to increase their $f_{\mathrm{o}}$. We hypothesized that ambulatory biofeedback could help extend the new vocal behavior to daily life.

This prospective case study assessed the impact of two weeks of ambulatory vibrotactile biofeedback (VTBF) applied to one transgender woman, following two weeks of voice therapy (three 60-minute sessions). The VTBF was activated when the participant's voice was lower than $150 \mathrm{~Hz}$ for more than $500 \mathrm{~ms}$ and was accompanied by two 60 -minute counseling sessions.

The results showed that mean $f_{\mathrm{o}}$ monitored in daily activities tended to increase following the two weeks of voice therapy ( $\Delta=8 \mathrm{~Hz}$ or 1 semitone) and then increased significantly immediately after the two weeks of VTBF $(\Delta=13 \mathrm{~Hz}$ or 1.5 semitones). The increase in mean $f_{\mathrm{o}}$ from day to day and the decrease in the activation percentage from the first to the second week of VTBF $(\Delta=6 \%)$ indicated a gradual integration of the motor behavior, making it possible to achieve the targeted female frequency.

The results suggest that ambulatory VTBF helped the participant to generalize the techniques acquired during the voice therapy sessions to real-life communication situations. These results are promising for therapeutic programs that integrate tools that can be used outside the clinical context.

Keywords: vocal motor behavior modification, voice feminization, transgender male to female, fundamental frequency, ambulatory vibrotactile biofeedback, voice monitoring, Rehabilitation Treatment Specification System 


\section{Introduction}

For some transwomen, sounding female is part of their transition process. Perceptually speaking, vocal femininity depends on several features: voice, including $f_{\mathrm{o}}$ and formant frequencies, articulation and intonation curves $[1,2]$. The role and weighting of each parameter in the perception of vocal femininity remains to be defined.

Although it is not the only parameter to be worked on, $f_{\mathrm{o}}$ remains a predominant parameter in the perception of female voice [3-7]. Many authors state that it must be raised to increase vocal femininity. According to Gelfer and Schofield [8], a speaking fundamental frequency above 156 to $160 \mathrm{~Hz}$ is necessary for others to perceive the speaker as female. The shorter the portion of discourse, the more perceived vocal femininity depends on a high spoken $f_{\mathrm{o}}[8-10]$. Some transgender women find that, despite their adoption of a higher $f_{\mathrm{o}}$, their voices continue to be perceived as male [4]. This situation can be evaluated using the Trans Woman Voice Questionnaire (TWVQ) [11]. This self-rated questionnaire identifies the issues facing people who want voice feminization and quantifies the effect of their current voice on their daily lives.

In addition to increasing $f_{\mathrm{o}}$, voice therapy for transgender women integrates exercises targeting breathing [7], adjustment of subglottal pressure [6], intonation curves [2], speech articulation, and resonance [1]. Once the patient accurately produces the voice behavior requested, the challenge is maintaining it in everyday speaking situations. This requires motor learning, defined by Schmidt and Lee (1975, in [12]) as "a set of processes associated with practice or experience leading to relatively permanent changes in the capability for movement." If a person cannot consistently control his/her motor behavior, the use of biofeedback may help. The Association for Applied Psychophysiology and Biofeedback defines biofeedback as "a process that enables an individual to learn how to 
change physiological activity for the purposes of improving health and performance" [13]. Precise ambulatory monitoring instruments give the user information about vocal function in real time, outside the clinic. Biofeedback could facilitate the acquisition of a new vocal motor behavior by generalizing its use in the patient's daily life. When biofeedback is applied, short-term behavior modification affects performance [14]. Once the appropriate behavior persists after the biofeedback is stopped, a relatively permanent change indicates maintenance of the behavior [14].

In the study by Stadelman-Cohen et al. (in [15], case no. 19, 157-163), ambulatory vibrotactile biofeedback (VTBF) was applied to a woman suffering from primary muscle tension dysphonia. As her voice quality improved at higher pitches, the aim was to increase her $f_{\mathrm{o}}$ and carry over therapy-induced vocal modifications outside of the voice therapy sessions. The ambulatory VTBF encouraged her not to drop below the $250 \mathrm{~Hz}$ threshold. The authors observed that she maintained a higher modal $f_{\mathrm{o}}$ when the VTBF was turned on than when it was turned off. In voice feminization, Södersten et al. [16] used ambulatory VTBF to increase $f_{\mathrm{o}}$ in a transgender woman who complained of not being able to maintain the desired $f_{\mathrm{o}}$ outside her therapy sessions. The authors were unable to conclude that VTBF had a positive impact, as the participant was not recognized as a woman on the basis of her voice. The lack of improvement might be due to the limited application of VTBF (15 hours) and the relatively low activation threshold $(130 \mathrm{~Hz})$.

The objective of this case study was to investigate the association between ambulatory VTBF and changes in $f_{\mathrm{o}}$ following voice therapy in a transgender woman. Three research questions guided this study: (1) Is an increase in $f_{\mathrm{o}}$ observed following the voice therapy sessions? (2) Is an increase in $f_{\mathrm{o}}$ observed following the ambulatory VTBF? (3) During the ambulatory VTBF, does the number of vibratory alerts decrease over time? On an exploratory basis, we describe the changes in results on the TWVQ. 


\section{Methods}

Ethical approval was obtained from the Ethics Committee of the Department of Psychology, Speech and Language Therapy, and Education at the University of Liège, Belgium (no. 20170131).

\subsection{Participant}

The participant was a transwoman in her twenties (the age range is presented in compliance with the General Data Protection Regulation). She had never received voice therapy for feminization. Her larynx was examined by an otorhinolaryngologist with videolaryngostroboscopy and was certified to be normal. Her hormone therapy started 12 months before the beginning of this study and comprised Androcur and Oestrogel. At the time of the study, she lived as a woman most of the time, especially in her private life. She held two part-time jobs: one in the field of IT and the other as a surface technician. For the second job, she dressed androgynously.

\subsection{Material}

The VoxLog (Sonvox, Umeå, Sweden) was used for both ambulatory data accumulation and VTBF. This portable voice dosimeter comprises a neck collar connected to an accumulation unit, which is fastened with a clip to the waistband. The collar contains a built-in air microphone and an accelerometer. For ambulatory data accumulation, the microphone measures both voice and background noise levels. The accelerometer detects skin acceleration due to vocal fold vibration and estimates $f_{\mathrm{o}}(\mathrm{in} \mathrm{Hz})$ using a Fast Fourier Transform algorithm. The device was used according to the manufacturer's instruction manual [17]. During the setup, it was possible to choose a time window of $0.1,1,5,30,60,180$, or 300 seconds. The time window determines the length of the interval during which VoxLog averages consecutive measurements to create one 
measurement sample. Short time windows are suitable for short recordings or when good time resolution is required, such as changes during a spoken sentence [17]. Long time windows are suitable for long recordings to investigate general behavior over longer periods of time [17]. In this study, the time window was set at 5 seconds, in order to achieve a compromise between time resolution and performance [17]. Within the 5second time window, the duration of each underlying measurement was $62.5 \mathrm{~ms}$, with a sliding window of $125 \mathrm{~ms}$. Note that $f_{\mathrm{o}}$ was not extracted from every frame, since it can only be detected when the sound is voiced and fully harmonic and $f_{\mathrm{o}}$ remains mostly constant over $125 \mathrm{~ms}$. Therefore, a 5-second time window can be based on a variable number of $f_{\mathrm{o}}$ that are averaged. The collected data were saved and analyzed in the accumulation unit.

Regarding biofeedback, the VoxLog provides wearers with VTBF about their voice sound pressure level or fundamental frequency. In this study, the $f_{\mathrm{o}}$ biofeedback option was used.

\subsection{Procedure}

This prospective study took place over seven consecutive weeks. For each week, table 1 displays the activated VoxLog function $\left(f_{\mathrm{o}}\right.$ monitoring only or $f_{\mathrm{o}}$ monitoring with biofeedback), the total monitoring duration per week and the mean duration of monitoring per day. The participant wore the VoxLog for a total of 471 hours. She kept a diary in which she recorded all the vocal events that occurred during the seven weeks of the study, along with her activities. Each day, she mentioned events related to her voice, classified in four categories (professional activities, private life, social life, and others). Examples included high vocal load or a quiet day without much talking, speaking in the presence of 
background noise, shouting, meeting with friends at a restaurant, VoxLog batteries dead, or health problems.

This is a post-peer-review, pre-copyedit version of an article published in International Archives of Occupational and Environmental Health.

\subsubsection{Evaluations and data analyses}

Evaluations took place at three time points during the study: evaluation $\mathrm{T} 1$ at week 1, evaluation T2 at week 4, and evaluation T3 at week 7. Each evaluation was done with the TWVQ and voice ambulatory measures. The TWVQ enabled the participant to express her voice-related problems in various situations [11]. Although this questionnaire has no cut-off score, the higher the score, the greater the complaints [11, 18]. Ambulatory measures focused primarily on $f_{\mathrm{o}}$ tracked using voice monitoring during daily activities.

Regarding the ambulatory measures, the participant wore the VoxLog dosimeter for one week at the three evaluation times (week 1, week 4, and week 7). She was instructed to behave and use her voice as usual. She paid attention to the contact of the collar with her neck and wore the device from the early morning for as long as possible.

VoxLog Discovery software was used for data importation and analysis. For each day, the program provided a mean value for $f_{\mathrm{o}}{ }^{1}$ Then, we calculated the mean weekly value (for week 1, week 4, week 5, week 6, and week 7). The first week (T1 evaluation) enabled us to measure $f_{\mathrm{o}}$ in ecological situations and establish the biofeedback activation threshold.

\footnotetext{
${ }^{1}$ Note that the mean of a non-normal distribution is sensitive to extreme values. Due to the skewed distribution of $f_{\mathrm{o}}$, it would have been more informative to provide the mode. This was not possible because the VoxLog dosimeter and VoxLog Discovery software have not been operational or supported by the manufacturer since 2017 .

This is a post-peer-review, pre-copyedit version of an article published in Logopedics Phoniatrics Vocology. The final authenticated version is available online at: http://dx.doi.org/ 10.1080/14015439.2021.1881158
} 


\subsubsection{Voice therapy sessions}

During weeks 2 and 3, the participant received three 60-minute voice therapy sessions with a voice therapist who has 20 years of experience working with transgender people. During this period, the participant did not wear the VoxLog. In table 2, the content of the therapy sessions is described a posteriori based on video recordings according to the Rehabilitation Treatment Specification System [19, 20]. The sessions focused primarily on the vocal parameters described by Morsomme and Remacle [21], which contribute to the perception of a female voice.

\subsubsection{Biofeedback and counseling}

The VoxLog $f_{\mathrm{o}}$ biofeedback was activated for two entire weeks (weeks 6 and 7) outside the clinic. The activation threshold was set at $150 \mathrm{~Hz}$, given the mean $f_{\mathrm{o}}$ measured at the T1 evaluation $(139 \mathrm{~Hz})$, the speaking fundamental frequency necessary for a transwoman to be perceived as female (>160 Hz [9]), and the participant's capacity to comfortably maintain a pitch $\geq 150 \mathrm{~Hz}$ on vowels and words. When the participant's voice was lower than $150 \mathrm{~Hz}$ for more than $500 \mathrm{~ms}$, the accumulation unit delivered a tactile feedback signal. According to Stadelman-Cohen et al. (in [15]), at less than $500 \mathrm{~ms}$, the feedback is triggered too often. The duration of the VTBF (feedback length) was set at $400 \mathrm{~ms}$, meaning that the unit delivered a vibration signal for $400 \mathrm{~ms}$. To prevent two successive signals from overlapping, the "sleep time" function was set at 1 second.

The two weeks of ambulatory VTBF were accompanied by two counseling sessions with the voice therapist. During the counseling, the diary completed by the participant made it possible to match the times when the VTBF was triggered with the activities being carried out at those times. Unlike the voice therapy sessions, the counseling involved analyzing the results of the vocal monitoring and VTBF activation. 
Advice was provided regarding the use of the tool, what the participant felt while wearing it and how to react when alerts went off. The strategies to be adopted to deal with vibratory alerts were identified with problem-solving techniques from cognitive behavioral therapy [22]. These strategies were discussed but not trained with vocal exercises; however, a connection was made with the exercises worked on during the voice therapy sessions. The voice therapy and counseling sessions had different contents.

\subsubsection{Analysis and statistics}

Statistica software (Windows 64-bit version) was used for statistical analysis. The mean $f_{\mathrm{o}}$ value (in $\mathrm{Hz}$ ) was obtained for each day of monitoring. In addition, the biofeedback activation percentage was obtained for each day of VTBF using the following formula: biofeedback activation percentage $=$ (number of feedback activations/number of observations)*100.

Due to the small sample size (one person) and the non-respect of the ANOVA applicability conditions (homoscedasticity and normality), we opted for non-parametric statistical analyses. For $f_{\mathrm{o}}$ (in $\mathrm{Hz}$ ), the Wilcoxon matched pairs tests allowed us to compare week 1 with week 4 (voice therapy effect) and week 4 with week 7 (VTBF effect). To account for multiple comparisons, the Bonferroni correction was applied (.05/2) and the p-value was set at .025. For the biofeedback activation percentage, the Wilcoxon matched pairs test allowed us to compare the two weeks of biofeedback, namely week 5 and week 6 , and the p-value was set at .05.

\section{Results}

\subsection{Descriptive data}

All the data gathered with the VoxLog during the study are presented in figure 1.

The black curve shows the mean $f_{\mathrm{o}}$ values per day. The gray bars represent the This is a post-peer-review, pre-copyedit version of an article published in Logopedics Phoniatrics Vocology. The final authenticated version is available online at: http://dx.doi.org/ 10.1080/14015439.2021.1881158 
biofeedback activation percentages. As described in table 1, vocal evaluations using the dosimeter took place in week 1, week 4 and week 7 . Weeks 2 and 3 were dedicated to voice therapy (no VoxLog measurements). Biofeedback was applied during weeks 5 and 6.

In general, we see an increase in $f_{\mathrm{o}}$, which was maintained above the $150 \mathrm{~Hz}$ threshold more consistently once the VTBF was activated. During the two weeks of VTBF, there is a gradual decline in the biofeedback activation rate.

\subsection{Fundamental frequency $\left(f_{\mathrm{o}}\right)$}

Mean $f_{\mathrm{o}}$ during week $1(139 \mathrm{~Hz}, \mathrm{SD} 4.5)$ was lower than during week 4 (147 Hz, SD 9.2). The Wilcoxon test showed that this difference of $8 \mathrm{~Hz}$ (1 semitone) was not significant $(\mathrm{p}=.091)$. Mean $f_{\mathrm{o}}$ during week $4(147 \mathrm{~Hz}, \mathrm{SD} 9.2)$ was significantly lower than during week $7(160 \mathrm{~Hz}, \mathrm{SD} 7.8)$. This revealed that, after the two weeks of VTBF, $f_{\mathrm{o}}$ increased by $13 \mathrm{~Hz}$ (1.5 semitones). The Wilcoxon test showed that this increase in $f_{\mathrm{o}}$ following the VTBF was statistically significant $(\mathrm{p}=.018)$.

\subsection{Biofeedback activation percentage}

The histogram in figure 1 illustrates a gradual decrease in the biofeedback activation percentage across weeks 5 and 6 . The mean biofeedback activation percentage during week $6(3 \%$, SD 1) was significantly lower than in week $5(9 \%$, SD 3$)(p=.001)$, indicating a decrease in biofeedback activation during that time.

\subsection{Transgender Woman Voice Questionnaire (TWVQ)}

The overall TWVQ score dropped from T1 (82/120), to T2 (72/120), to T3 (68/120), indicating a decrease in voice-related complaints. Fourteen points separated the overall scores at T1 and T3. The sub-score in the domain of psychosocial consequences 
of voice improved considerably $(\mathrm{T} 1=34 / 48 ; \mathrm{T} 2=24 / 48 ; \mathrm{T} 3=22 / 48)$, while the subscore related to voice functioning did not show a clear trend over time $(\mathrm{T} 1=36 / 56 ; \mathrm{T} 2=$ 38/56; T3 = 34/56) [23]

\section{Discussion}

\subsection{Voice therapy sessions}

The three voice therapy sessions ( 3 X 60 minutes) had no immediate significant effect on $f_{\mathrm{o}}$, although figure 1 shows that mean daily $f_{\mathrm{o}}$ tended to increase over weeks 2 and 3. As described in table 2, the content of the sessions was dense. We know that, compared to treatment for dysphonia, transgender women may need more time before the benefits of voice therapy sessions appear [3]. A longer practice time during the sessions might also have induced significant changes. Nevertheless, the higher frequency values after the treatment (evaluation T2, week 4) suggest that the advice provided at the sessions was helpful in raising $f_{\mathrm{o}}$.

The acquisition of a new behavior goes through several stages, such as the discovery of the vocal motor action, which demands introspection about one's own functioning, and then the ability to copy the desired action by applying the suggested strategies. To do this, Schmidt [24] and Iwarsson [25] recommend breaking movements down, providing an example and then giving feedback on the speaker's production. The voice therapist scrupulously followed this model. The action can become automated if it is repeated and trained regularly. The participant practiced the exercises at home with the help of audio recordings made during the sessions. Nevertheless, understanding, memorizing, integrating and copying a vocal motor behavior vary considerably from one individual to another. These skills are related to metacognition [26], which requires the participant to pay attention to her motor actions, question herself, and be able to change 
her behavior outside the voice therapy sessions. In the case of the transwoman participant, integrating the new vocal behavior into her daily life proved to be difficult or embarrassing at times when she was with colleagues or friends; their reactions influenced her attempts and may have inhibited the desired vocal motor behavior. For example, she confided that her friends no longer recognized her voice. Since voice is an integral part of identity, any change can impact recognition [21, 27].

\subsection{Ambulatory vibrotactile biofeedback (VTBF)}

Over the two weeks of ambulatory VTBF, the gradual increase in $f_{\mathrm{o}}$ and the concomitant decrease in biofeedback activation percentage indicate a gradual integration of the motor behavior required to achieve the targeted female frequency. These results do not corroborate those of Södersten et al. [16], who fitted a transgender woman with an ambulatory VTBF device with the aim of ensuring that she would maintain the $f_{\mathrm{o}}$ defined in her voice therapy sessions during her daily life. In that case, the VTBF did not have the intended effect. Compared to our study, the activation threshold was lower $(130 \mathrm{~Hz}$ vs. $150 \mathrm{~Hz}$ ) and the duration of the VTBF activation was shorter (15 hours vs. 198 hours), which scarcely gave the participant time to familiarize herself with the equipment.

In this study, accompaniment during the VTBF took the form of two counseling sessions, one each week in weeks 5 and 6. During both sessions, advice was provided regarding how to use the tool, what the participant felt while using it and what to do when alerts went off. Problem-solving techniques from cognitive behavioral therapy [22] were mainly used during the counseling sessions. They were intended to identify strategies to deal with VTBF alerts.

While the participant was wearing the dosimeter with ambulatory VTBF, the descriptive data on biofeedback activation (figure 1) reveal a progressive decrease. 
Statistical analysis showed that the VTBF activation was significantly lower in week 6 than in week 5 . The rate decreased from a mean of $12 \%$ alert activations at the start of week 5 to $9 \%$ at the end of week 5 , and then less than $5 \%$ in week 6 . The advice given before and during the VTBF use proved to be crucial and enabled the participant to adapt to the tool. For example, when the alert went off, she remembered the exercises she had practiced during the sessions and then managed to reproduce the target of $150 \mathrm{~Hz}$ or higher. She used the device mainly for the kinesthetic sensations it created, and the functional sentences she had trained with gave her almost automatic access to the necessary motor actions. During the counseling session, thanks to the diary, the voice therapist and the participant were able to relate the times when activation rates were high with the activities described at the same points. For example, two situations she found hard to manage were an evening at a restaurant and an evening with friends who teased her a lot. We were also able to identify points when VTBF activation was low, corresponding to a period when the participant was ill. We think that the first week of VTBF (week 5) enabled her to go through two stages: familiarization with the tool and becoming aware of her everyday $f_{\mathrm{o}}$. During the second week of VTBF (week 6), the results suggest that she had mastered the performance stage, namely modification of her vocal motor behavior when the VTBF was applied. During week 7 , the maintenance of $f_{\mathrm{o}}$ above the $150 \mathrm{~Hz}$ threshold without VTBF suggests that the participant accurately produced the required $f_{\mathrm{o}}$ behavior.

Based on this study of voice feminization, two weeks of ambulatory VTBF seem to be sufficient to induce an increase in $f_{\mathrm{o}}$. Nevertheless, the reduction in $f_{\mathrm{o}}$ at T3 suggests that the effect fades. In the absence of a later post-test, we cannot reach any conclusions about long-term retention of the change. 


\subsection{Participant's perception}

The participant's overall scores on the TWVQ [11] decreased from T1 to T3, with a greater decrease after the therapy sessions (T2). Recall that higher scores indicate more complaints. It was in the domain related to the psychosocial consequences of voice that her scores decreased the most; the items related to functional impact of the voice do not show a clear trend throughout the study [23]. The muscle efforts that the participant made demanded a lot of energy. Although she still reported some difficulties, practicing the achievement of higher $f_{\mathrm{o}}$ in her daily life seemed to be more positive, given the decrease in psychosocial consequences scores.

Once the study was over, the participant was asked about her experiences. She said that, since the end of the study, she no longer thought about her $f_{\mathrm{o}}$ as she was more concerned with day-to-day events. Some authors talk about the phenomenon of extinction [28]: when the reinforcement is removed, the expected behavior decreases, but it is not forgotten. A long-term follow-up of $f_{o}$ would be worthwhile to attempt to detect this phenomenon.

\subsection{Limitations}

This paper reports an exploratory study of a single case. A randomized trial with a larger sample is necessary before any conclusions can be drawn about the efficacy of ambulatory VTBF in voice feminization therapy. Similarly, the program may have to last longer to better verify the changes in $f_{\mathrm{o}}$ and biofeedback activation percentage over time. A long-term follow-up would help to monitor retention of the change. Moreover, this study did not take into account the measures of voice and background noise levels, which are known to influence voice $f_{\mathrm{o}}$.

Finally, we did not experiment with progressively decreasing feedback. Several authors suggest that one should first use continuous reinforcement (reinforcement of 
every response) and then gradually introduce partial reinforcement (non-systematic reinforcement) $[29,30]$. This procedure would make it possible not to stop the VTBF abruptly and thus to better maintain acquired behaviors.

\section{Conclusion}

This study of a transgender woman showed a non-significant increase in $f_{\mathrm{o}}$ after voice therapy, followed by a significant increase during the week directly after VTBF and counseling. The increase in $f_{\mathrm{o}}$ and concomitant decrease in the VTBF activation rate reveal progressive integration of a motor behavior that would achieve the targeted female frequency. These findings suggest that the VTBF did allow the participant to apply the techniques she had acquired during the therapy sessions in her real life. However, the absence of a later post-test prevents us from drawing any conclusions about long-term maintenance of the change.

The results of real-time, every-time VTBF for two weeks are promising for a therapeutic program that integrates tools that can be used outside the clinic. Future studies should investigate the impact of a longer period of biofeedback, modifications of feedback frequency (e.g., reduced cueing), timing (e.g., delayed feedback), and thresholds (e.g., progressive difficulty).

\section{Acknowledgments}

Angélique Remacle was supported by the Fund for Scientific Research - FNRS (F.R.S.FNRS, Brussels, Belgium). We thank Clémentine Jacquet for her help in collecting the data. 


\section{References}

1. Leung Y, Oates J, Chan SP. Voice, articulation, and prosody contribute to listener perceptions of speaker gender: a systematic review and meta-analysis. J Speech Lang Hear Res. 2018;61(2):266-297.

2. Thornton J. Working with the transgender voice: the role of the speech and language therapist. Sexologies 2008;17(4):271-276.

3. Hancock AB, Garabedian LM. Transgender voice and communication treatment: a retrospective chart review of 25 cases. Int $\mathrm{J}$ Lang Commun Disord. 2013;48(1):54-65.

4. Dacakis G. Long-term maintenance of fundamental frequency increases in maleto-female transsexuals. J Voice. 2000;14(4):549-556.

5. Iseli M, Shue Y, Alwan A. Age, sex, and vowel dependencies of acoustic measures related to the voice source. J Acoust Soc Am. 2007;121(4):2283-2295.

6. Mészáros K, Csokonai Vitéz L, Szabolcs I, et al. Efficacy of conservative voice treatment in male-to-female transsexuals. Folia Phoniatr Logop. 2005;57(2):111118.

7. Söderpalm E, Larsson A, Almquist S.-Å. Evaluation of a consecutive group of transsexual individuals referred for vocal intervention in the west of Sweden. Logop Phoniatr Vocol. 2004;29(1):18-30.

8. Gelfer M, Schofield K. Comparison of acoustic and perceptual measures of voice in male-to-female transsexuals perceived as female versus those perceived as male. J Voice. 2000;14(1):22-33.

9. Gorham-Rowan M, Morris R. Aerodynamic analysis of male-to-female transgender voice. J Voice. 2006;20(2):251-262. 
10. Wolfe VI. Intonation and fundamental frequency in male-to-female transsexuals. J Speech Hear Disord. 1990;55(1):43-50.

11. Morsomme D, Revis J, Thomas E. Translation, adaptation, and preliminary validation of Dacakis and Davies' “Transsexual Voice Questionnaire (Male to Female)" in French. J Voice. 2019;33(5):807.e813-807.e824.

12. Maas E, Robin DA, Austermann Hula SN, et al. Principles of motor learning in treatment of motor speech disorders. Am J Speech Lang Pathol. 2008;17:277298.

13. Association for Applied Psychophysiology and Biofeedback. Home page. https://www.aapb.org/i4a/pages/index.cfm?pageid=3463

14. Van Stan JH, Mehta DD, Hillman RE. The effect of voice ambulatory biofeedback on the daily performance and retention of a modified vocal motor behavior in participants with normal voices. J Speech Lang Hear Res. 2015;58(3):713-721.

15. Stemple J, Hapner E. Voice therapy: clinical case studies. San Diego (CA): Plural Publishing; 2014.

16. Södersten M, Hertegård S, Larsson H, et al. Use of ambulatory biofeedback for transsexual male-to-female clients. Manual-ambulatory phonation monitor: applications for speech and voice [software manual]. Montvale (NJ): KayPENTAX; 2009.

17. VoxLog Instruction Manual. Version D1.2. Sonvox, Umeå, Sweden; 2015.

18. Dacakis G, Davies S, Oates J, et al. Development and preliminary evaluation of the Transsexual Voice Questionnaire for Male-to-Female Transsexuals. J. Voice. 2013;27(3):312-320. 
19. Van Stan JH, Dijkers MP, Whyte J, et al. The rehabilitation treatment specification system: implications for improvements in research design, reporting, replication, and synthesis. Arch Phys Med Rehabil. 2019;100(1):146-155.

20. Hart T, Dijkers MP, Whyte J, et al. A theory-driven system for the specification of rehabilitation treatments. Arch Phys Med Rehabil. 2019;100(1):172-180.

21. Morsomme D, Remacle A. Féminiser la voix [Voice feminization]. In: KleinDallant C, editor. De la voix parlée au chant: Bilans, rééducations, pathologies de la voix parlée et chantée [From spoken voice to song: Reports, rehabilitation, pathologies of the speaking and singing voice]. Paris: C Klein-Dallant; 2016. p. 327-340. French.

22. D'Zurilla TJ, Nezu AM. Problem-solving therapy: a treatment manual. New York (NY): Guilford Press; 2010.

23. Dacakis G, Oates J, Douglas JM. Further evidence of the construct validity of the transsexual voice questionnaire (TVQMtF) using principal components analysis. J Voice. 2016;31(2),142-148.

24. Schmidt RA. A schema theory of discrete motor skill learning. Psychol Rev. $1975 ; 82(4): 225-260$.

25. Iwarsson J. Facilitating behavioral learning and habit change in voice therapy theoretic premises and practical strategies. Logop Phoniatr Vocol. 2015;40(4):179-186.

26. Andrieux M. Autocontrôle et adaptation de la difficulté dans l'apprentissage d'une habileté motrice [Self-control and adaptation of difficulty in learning a motor skill] [dissertation]. Toulouse: Université de Toulouse III-Paul Sabatier; 2011. French. 
27. Arnold A. Voix et transidentité: changer de voix pour changer de genre? [Voice and transidentity: the role of the voice in gender perception] Langage Société. 2015;151(1):87-105. French.

28. Kirsch I, Lynn SJ, Vigorito M, et al. The role of cognition in classical and operant conditioning. J Clin Psychol. 2004;60(4):369-392.

29. Weeks DL, Kordus RN. Relative frequency of knowledge of performance and motor skill learning. Res Q Exerc Sport. 1998;69(3):224-230.

30. Steinhauer K, Grayhack JP. The role of knowledge of results in performance and learning of a voice motor task. J Voice. 2000;14(2):137-145. 
Table 1. Study procedure applied to a transwoman over the seven consecutive weeks of the case study.

\begin{tabular}{|c|c|c|c|c|c|c|c|}
\hline & $\begin{array}{c}\text { Week 1 } \\
\text { Evaluation T1 }\end{array}$ & $\begin{array}{c}\text { Week } 2 \\
\text { Voice therapy }\end{array}$ & $\begin{array}{c}\text { Week } 3 \\
\text { Voice therapy }\end{array}$ & $\begin{array}{c}\text { Week } 4 \\
\text { Evaluation T2 }\end{array}$ & $\begin{array}{c}\text { Week 5 } \\
\text { Biofeedback and } \\
\text { counseling }\end{array}$ & $\begin{array}{c}\text { Week 6 } \\
\text { Biofeedback and } \\
\text { counseling }\end{array}$ & $\begin{array}{c}\text { Week } 7 \\
\text { Evaluation T3 }\end{array}$ \\
\hline $\begin{array}{l}\text { VoxLog } \\
\text { dosimeter } \\
\text { function activated }\end{array}$ & $f_{\mathrm{o}}$ monitoring & I & I & $f_{\mathrm{o}}$ monitoring & $\begin{array}{c}f_{\mathrm{o}} \text { monitoring } \\
f_{\mathrm{o}} \text { VTBF }\end{array}$ & $\begin{array}{c}f_{\mathrm{o}} \text { monitoring } \\
f_{\mathrm{o}} \text { VTBF }\end{array}$ & $f_{\mathrm{o}}$ monitoring \\
\hline $\begin{array}{l}\text { Total duration of } \\
\text { monitoring per } \\
\text { week [hours; } \\
\text { minutes] }\end{array}$ & $94 ; 30$ & I & I & $91 ; 23$ & $100 ; 05$ & $98 ; 07$ & $87 ; 17$ \\
\hline $\begin{array}{l}\text { Mean duration of } \\
\text { monitoring per } \\
\text { day [hours; } \\
\text { minutes] } \\
\text { (min-max) }\end{array}$ & $\begin{array}{c}13 ; 31 \\
(11 ; 49-14 ; 03)\end{array}$ & 1 & 1 & $\begin{array}{c}13 ; 04 \\
(11 ; 12-14 ; 03)\end{array}$ & $\begin{array}{c}13 ; 36 \\
(12 ; 09-14 ; 03)\end{array}$ & $\begin{array}{c}14 ; 02 \\
(12 ; 05-16 ; 53)\end{array}$ & $\begin{array}{c}12 ; 29 \\
(8 ; 58-15 ; 44)\end{array}$ \\
\hline
\end{tabular}


Table 2. Therapy description according to the Rehabilitation Treatment Specification System (RTSS) $[19,20]$

\begin{tabular}{|c|c|c|c|}
\hline \multicolumn{2}{|c|}{ Targets } & \multicolumn{2}{|c|}{ Ingredients } \\
\hline $\begin{array}{l}\text { What/In what } \\
\text { way }\end{array}$ & Group & Ingredient & Dosing parameter \\
\hline $\begin{array}{l}\text { 1. Decrease } \\
\text { tension in } \\
\text { neck } \\
\text { muscles / } \\
\text { subjective } \\
\text { measure of } \\
\text { muscle } \\
\text { tension by } \\
\text { palpation }\end{array}$ & Organ functions & $\begin{array}{l}\text { Digit manipulations by the } \\
\text { voice therapist while the } \\
\text { participant is at rest (i.e., } \\
\text { kneading the } \\
\text { sternocleidomastoid and } \\
\text { trapezius muscles) and } \\
\text { voicing (i.e., digit } \\
\text { monitoring of larynx } \\
\text { mobility on pitch glides) }\end{array}$ & $\begin{array}{l}\sim 5 \text { min. at the } \\
\text { beginning of each } \\
\text { voice therapy } \\
\text { session. Sufficient } \\
\text { digit pressure was } \\
\text { applied to resist } \\
\text { the patient's } \\
\text { excessive muscle } \\
\text { activation }\end{array}$ \\
\hline $\begin{array}{l}\text { 2. Increase } \\
\text { formant } 2 \\
\text { and } 3 \\
\text { frequency/ } \\
\text { perceptual } \\
\text { evaluation }\end{array}$ & Skills and habits & $\begin{array}{l}\text { - Instruct the participant on } \\
\text { how to reach anterior } \\
\text { resonance (e.g., lip } \\
\text { spreading and protrusion, } \\
\text { tongue carry-over, } \\
\text { humming) } \\
\text { - Provide opportunities for } \\
\text { the participant to practice } \\
\text { anterior resonance in a } \\
\text { hierarchy of difficulty: } \\
\text { sustained vowels, } \\
\text { syllables, sentences, } \\
\text { reading, spontaneous } \\
\text { speech, singing } \\
\text { - Provide feedback on the } \\
\text { participant's vocal } \\
\text { performance using a } 10- \\
\text { point scale (1 = worst and } \\
10=\text { best) } \\
\text { Instruct the participant on } \\
\text { how to increase formant } 2 \\
\text { and } 3 \text { frequency while } \\
\text { humming at home }\end{array}$ & $\begin{array}{l}\text { Throughout the } \\
\text { three voice } \\
\text { therapy sessions } \\
\text { Repetition of the } \\
\text { exercise until } \\
\text { about } 80 \% \\
\text { accuracy before } \\
\text { moving on to the } \\
\text { next exercise } \\
1 \text { feedback } \\
\text { score/exercise }\end{array}$ \\
\hline $\begin{array}{l}\text { 3. Achieve } \\
\text { feminine } \\
\text { intonation } \\
\text { patterns / } \\
\text { perceptual } \\
\text { evaluation }\end{array}$ & & $\begin{array}{l}\text { - Instruct the participant on } \\
\text { how to modulate her pitch } \\
\text { (increase pitch flexibility, } \\
\text { inflection, and intonational } \\
\text { contrasts) } \\
\text { - Provide opportunities for } \\
\text { the participant to practice } \\
\text { feminine intonation } \\
\text { patterns in a hierarchy of } \\
\text { difficulty: sustained } \\
\text { vowels, syllables, }\end{array}$ & $\begin{array}{l}\text { Throughout the } \\
\text { three voice } \\
\text { therapy sessions } \\
\text { Repetition of the } \\
\text { exercise until } \\
\text { about } 80 \% \\
\text { accuracy before } \\
\text { moving on to the } \\
\text { next exercise }\end{array}$ \\
\hline
\end{tabular}




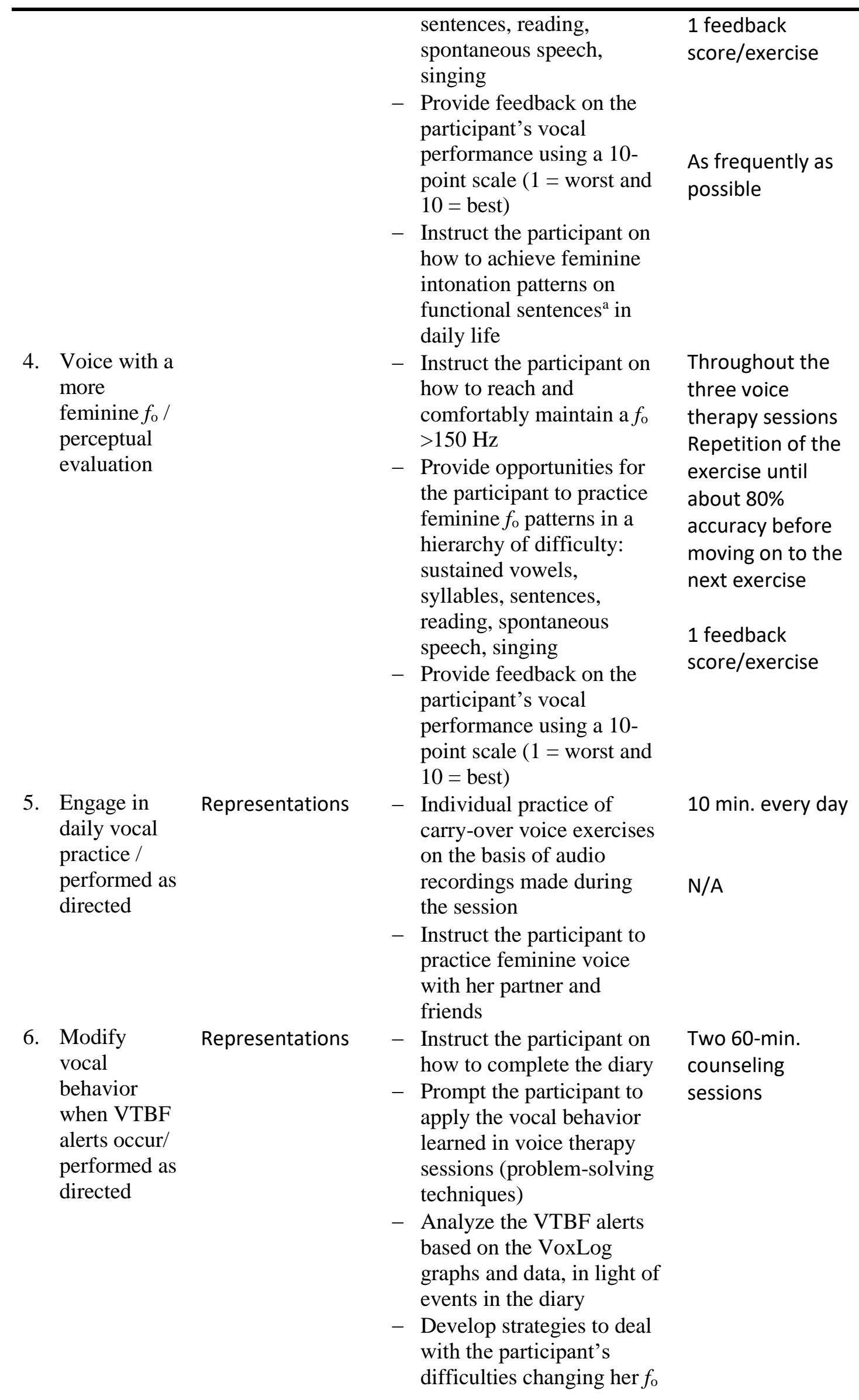

This is a post-peer-review, pre-copyedit version of an article published in Logopedics Phoniatrics Vocology. The final authenticated version is available online at: http://dx.doi.org/ 10.1080/14015439.2021.1881158 


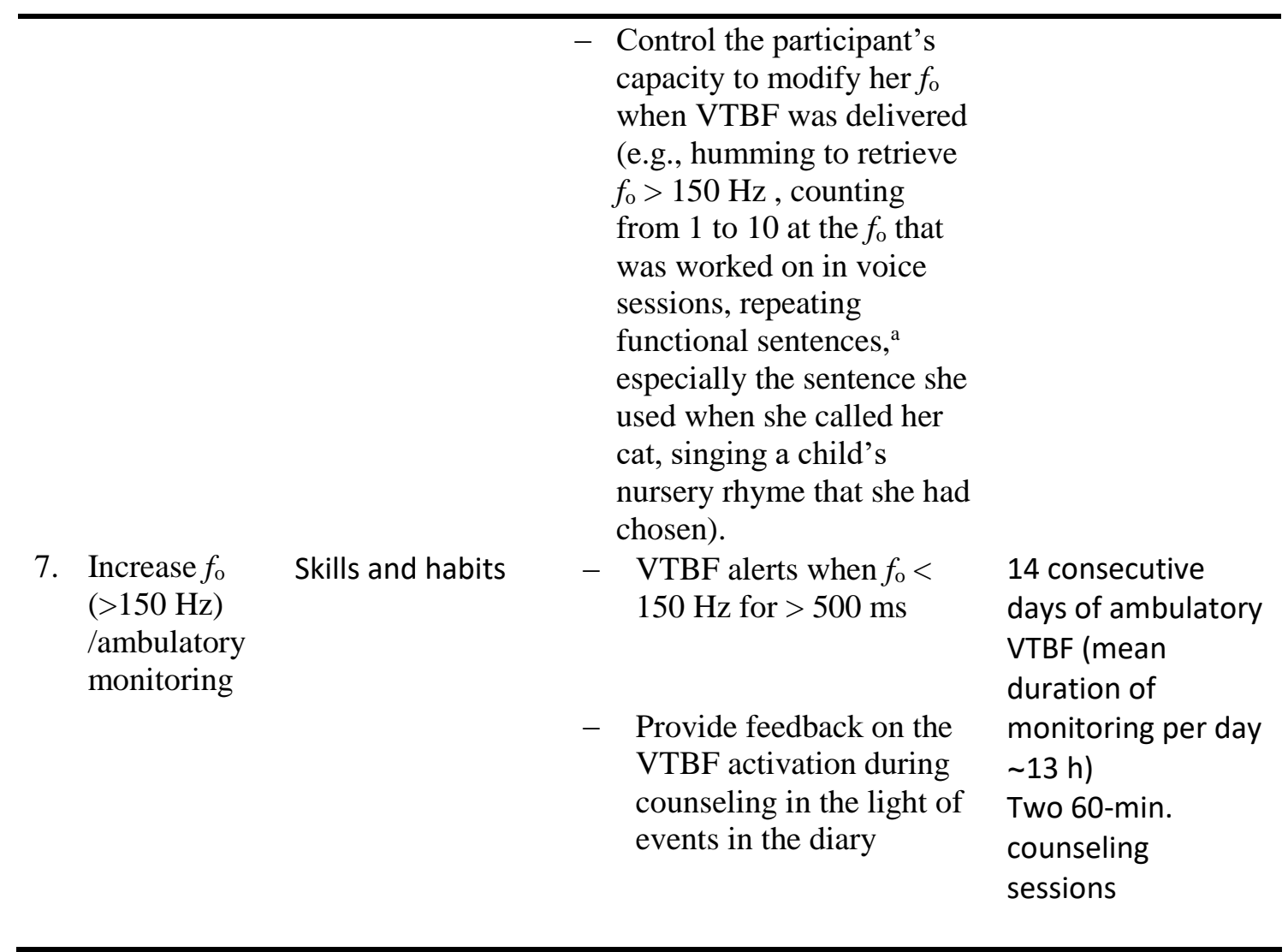

Legend: VTBF $=$ vibrotactile biofeedback

${ }^{a}$ Ten functional sentences were chosen to incorporate the expressions the participant used most commonly in her daily life. The aim of these target sentences was to facilitate the transfer of the female voice patterns learned in the training sessions into daily life. 
Figure 1. Changes in daily mean voice $f_{\mathrm{o}}$ and biofeedback activation percentage over the seven consecutive weeks of the study.

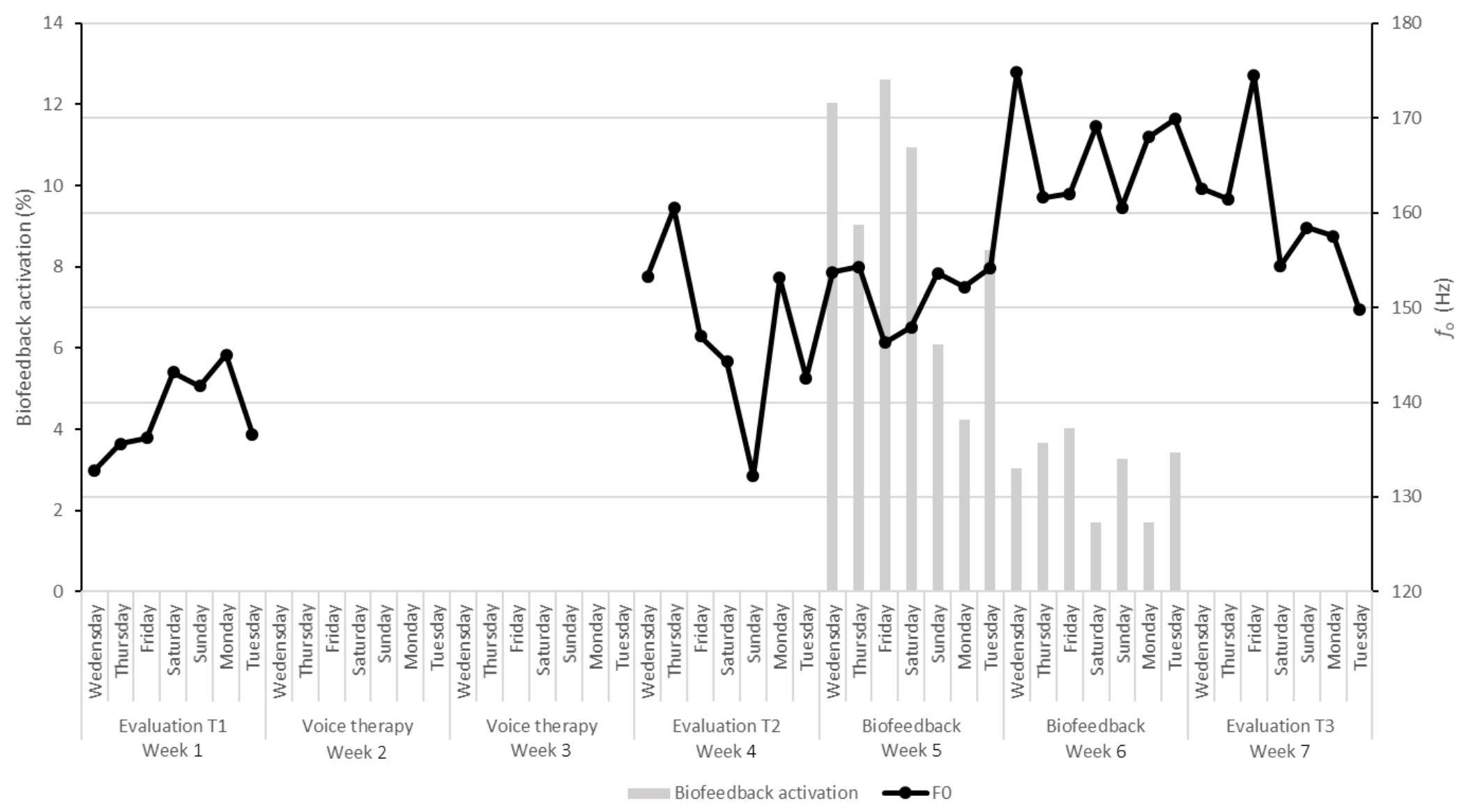

Legend. The $\mathrm{x}$-axis depicts each day of the study. The left y-axis depicts the biofeedback activation (\%) and the right y-axis represents the fundamental frequency $\left(f_{\mathrm{o}}\right.$, in Hertz)

This is a post-peer-review, pre-copyedit version of an article published in Logopedics Phoniatrics Vocology. 